\title{
Some aspects of the health status of homeless people
}

\section{Bartošovič}

St. Elisabeth University of Health and Social Sciences, Bratislava

Doležalova 12, 90901 Skalica, Slovak republic

Declaration: There is no conflict of interest

Submitted: 22.1.2016 Revised: 19.3.2016 Accepted: 3.4.2016

\section{Reviewers:}

Urbanus M. Ndolo

Deputy, HOD and Co-ordinator of Block Field Attachments,

Dept. of Social Sciences, Catholic University of Eastern Africa, Nairobi, Kenya

Z. Szarota

Pedagogical University of Cracow, Poland

\section{Key words:}

Homeless, nutrition, infectious diseases, tuberculosis, trauma, health care, hospitalization, health status, ageing, death.

\section{Abstract}

Spectrum of infections and non-infections diseases among refuges from Syria/Iraq to Hungary/ Austria in September 2015 is analyzed. Respiratory isolates from patients with pneumonia were obtained from respiratory tract secretions and tested for antimicriobial susceptibility. Majority of ID were upper and lower respiratory tract infections, scabies and other skin and soft tissue infections. However, infections represented only about one half of cases seeking medical help - the rest 40-60\% were hypertension, exhaustion, depression, diabetes, neuropsychiatric disorders.

\section{Abstract}

$40 \%$ of homeless people report at least one chronic health problem. Some medical problems are particularly prevalent such as chronic obstructive pulmonary diseases, arthritis and musculoskeletal disorders. Trauma is a significant cause of disability and death. Homeless people are predisposed to infections because of their poor physical state and lack of hygiene; hence outbreaks of contagious diseases are more prevalent in the homeless. Tuberculosis is an important health problem among the homeless. Homeless people are at high risk of bloodborne infections and disproportionately suffer from mental illness and substance use disorders. Homelessness negatively impacts child health and development. There are a number of internal and external barriers to providing health care for homeless persons. Hospitalizations are more frequent and they take a longer time. The homeless are not registered with their Doctor and try to get health assistance by using emergency services. They have problems with health system or social insurance. The health status is substantially worse than in other population. Homeless people have a greatly 
increased risk of death. Problems of providing health care to the homeless depend in every country on the existing health policy and the economy. Insufficient care for homeless people means not only aggravation of their health state but it could have negative impacts on the health of the broader group of people.

\section{Background}

Definitions of homelessness vary across countries (1). In line with its simplified definition homeless people are the human beings living on the street with no roof above their heads and no place to stay even for a short time (2). In 2005, a typology named ETHOS (European Typology of Homelessness and Housing Exclusion) worked to serve the needs of the European Union. This typology was elaborated by another national organization called FEANTSA (Fédération Européenne d'Associations Nationales Travaillant avec les Sans-Abris) (3). ETHOS classifies people according to their living situation:

- rooflessness (without a shelter of any kind, sleeping rough),

- houselessness (with a place to sleep but temporary in institutions or shelter),

- living in insecure accomodation (threatened with severe exclusion due

to insecure tenancies, eviction, domestic violence),

- living in inadequate housing (caravans, unfit housing, extreme overcrowding) (4).

The exact number of homeless pople is unknown. In the whole of the European Union an estimated 4.1 million people have a homeless episode in a year (5). Czech Republic estimates to have about 100,000 homeless people; a census of homeless people in Prague identified 3,096 people in this category (6). Slovakia accounts for about
30,000 homeless people living mostly in Bratislava (approximately 3,000 people data from 2006) $(7,3)$.

Reasons leading to homelessness are Objective and Subjective.

Objective (structural) factors including the general social situation, e.g. employment policy;

housing policy; relationship of society to these marginal groups.

Subjective (individual) factors are represented by material factors (e.g. loss of home, loss of

job, insufficient incomes, loss of a property, etc.);

Relationship factors (e.g. family or marital problems, divorce, split up of a family, violence

in a family, loneliness);

Personal factors (e.g. mental or somatic disease, disability, alcoholism and other addictions); Institutional factors (release from hospital or prison, departure from children's home) (6).

To conclude: negative personal relations; work or housing problems; financial problems; administrative-legal problems; health problems belong to the most serious problems facing homeless people $(6,8)$.

\section{Chronic Diseases and Nutrition}

$40 \%$ of homeless persons report at least one chronic health problem. These chronic illnesses may be silent until late in their courses and, because of limited medical attention, often go under recognized and untreated. Even if the condition is detected and treated, lack of compliance with consistent follow-up often results in disease progression, disability, morbidity and premature death (9). A Slovak study made in a homeless shelter demonstrated that $42.5 \%$ of homeless people suffered from infectious diseases (mostly respiratory and urinary 
infections), while $57.4 \%$ of homeless people suffered from non-infectious diseases; the most frequent being ischemic heart disease and hypertension (10). Epilepsy belongs to the frequent diseases, as well. Prevalence of active epilepsy (8.1\%) in a French study is markedly higher than that estimated in the general population $(<1 \%)$. When alcohol-related seizures (ARS) are included, $14.5 \%$ of a study population had a history of seizures (11). Some medical problems are particularly prevalent with homeless persons; chronic obstructive pulmonary diseases, arthritis and musculoskeletal disorders. Hypertension, diabetes and anemia are often insufficiently controlled and may be unrecognizable for a long period of time. Hygiene and tooth care are at a low level (12).

The way of life of homeless people results in problems respecting the so-called healthy lifestyle regimen. We can hardly speak of a healthy way of living in a situation when people are able to satisfy their biological needs just occasionally and/or in a substitute way (13). Homeless persons depend substantially on food from municipal and charitable shelters, fast-food restarurants, delicatesssens and garbage bins (14). Most studies report a high prevalence of inadequate or imbalanced nutritiment, vitamin and mineral intake placing the homeless at risk for nutrion-related disorders and contributing to the increased prevalence of poorly controlled diabetes, hypertension and cholesterol; all risk factors for cardiovascular diseases (15). Diets of homeless people are often high in saturated fats and cholesterol and inadequate in essential nutrients contributing to adverse lipid profiles (15).

\section{Trauma}

Trauma is a significant cause of disability and death. The homeless are particularly at risk because life in the city streets is unsafe and they may choose hazardous sleeping accommodations and suffer from burns caused by fires used for warmth (16). In a study of 581 homeless female veterans 99\% of participants endorsed at least one trauma item; the homeless women reported being exposed to a mean of 7.40 different types of trauma and a median of 31 total events (17). The rate of traumatic brain injury varied across studies, ranging from $8 \%-53 \%$. Homeless men are more likely to have traumatic brain injury than homeless women $(1,18)$. Hwang and colleagues found a high prevalence of traumatic brain injuries that are 5 or more times greater than the lifetime prevalence rate of the general population in the United States. The history of traumatic brain injuries was strongly associated with seizures, mental health problems, drug problems, and poorer physical and mental health states (19).

\section{Infectious diseases}

Homeless people are predisposed to infections because of their poor physical state and lack

of hygiene; hence outbreaks of contagious diseases are more prevalent in the homeless (20). Skin problems are the main reason why the homeless seek medical attention, and these commonly include scabies, pediculosis, tinea infections and impetigo (20). The louse transmitted bacteria Bartonella qiuntana has been found to cause clinical conditions in the homeless such as urban trench fever, bacillary angionmatosis, endocarditis, and chronic afebrile bacteriaemia (20). Foot problems are a major cause of illness and may represent up to $20 \%$ of the medical complaints of homeless people. The main cause of foot lesions is minor repetitive trauma because the homeless often walk in inappropriate shoes. Other factors are venous stasis and leg edema; cold (frost bite) and moisture (immersion foot); peripheral neuropathy; high 
prevalence of hypertension; heavy tobacco use; lack of hygiene.

The combination of trauma, stasis and ischemia in the feet promotes infections which may result in osteomyelitis, cellulitis and gangrene and necessitate amputation of the limb (20).

Respiratory diseases are very frequent. Common viral respiratory diseases are easily transmitted from person to person. Crowded shelters and food lines provide the ideal circumstances for the spread of respiratory infections (16). Minor upper respiratory infections have been found to be twice as common in homeless children and represent $40 \%$ of the acute medical complaints of the homeless (20). Homeless persons are at high risk of serious pneumococcal infections. In Toronto, the incidence of invasive pneumococcal disease in homeless adults was 273 infections per 100,000 persons per year compared to 9 per 100,000 persons in the general adult population. Homeless persons with invasive pneumococcal disease were younger than other adults, more likely to be smokers, to abuse alcohol and to use intravenous drugs. The proportion of patients with recurrent disease was five times higher in case of the homeless than with other adults (12\% vs. 2.5\%) (21).

\section{Tuberculosis}

Tuberculosis is an important health problem among the homeless. Persons living in shelters are at high risk of tuberculosis and also pose a potential public health problem (16). In systematic review and meta-analysis (43 eligible surveys with a total population of 59,736 homeless individuals) authors reported that estimates of tuberculosis prevalence range from $0.2 \%$ to $7.7 \%$ (22). Tuberculosis in Prague increased from $2.1 \%$ in 1999 to $15.1 \%$ in 2008 (23). In 2002-2006, the homeless suffered from tuberculosis on average 10 times more often than the other population (24). Tuberculosis in the homeless has some specific features:

- mainly men are affected;

- ill people in a productive age of 4060 years significantly prevail;

- tuberculosis is found in its symptomatic state only, active search is applied just with difficulties;

- a high percentage of tbc is found in moribund state or with dead homeless persons;

- multi-resistent forms of tuberculosis also appear among the homeless (23).

\section{Bloodborne Infections}

Homeless people are at high risk for bloodborne infections. HIV infection, viral hepatitis $B$, viral hepatitis $C$ occur more often than in other populations due to more frequent prostitution to earn money to survive and/or get a daily drug dose. Homelessness is also an important risk factor for acquiring HIV infection. Data from the USA showed that higher intravenous drug use, prostitution or "survival sex" and multiple sexual partners contribute to increased HIV prevalence (20). AIDS and homelessness co-occur at very high rates: AIDS is nine times more prevalent among the homeless in Philadelphia than in the general population, and homelessness is three times more prevalent among people with AIDS than in the general population. Among the homeless, being male, having a substance abuse problem and having a severe mental disorder were all significant risk factors for AIDS (25). In the above- mentioned review the prevalence of hepatitis $\mathrm{C}$ virus infection ranged from $3.9 \%$ to $36.2 \%$ (22). The prevalence of hepatitis B and hepatitis C are significantly higher among street youth than among non-street persons of similar age. A study of the prevalence of hepatitis B infection in street youth in Montreal found that $9.2 \%$ of the participants had markers 
of the infection. Risk factors such as older age ( $>18$ years); injection drug use; sexual partners with history of unspecified hepatitis, $\geq 1$ tattoo and body piercing were the factors associated with $\mathrm{HBV}$ infection (26). In the survey of hepatitis $\mathrm{B}$ and $\mathrm{C}$ prevalence amongst ninety-eight individuals of the Prague homeless community, the authors found that prevalence of both VHB and VHC achieved $26.5 \%$. Risk factors were current or past intravenous drug users, higher age (21 years and older) and sharing paraphernalia (equipment used in the preparation of drugs for injection, e.g. spoons, filters and foil) (27).

\section{Mental Disorders and Addictions}

Homelessness can be both a cause and a consequence of mental illness (31). The homeless disproportionately suffer from mental illness and substance use disorders. In one survey, $81 \%$ of patients had a major mental illness; $69 \%$ had a substance-use disorder. Over $50 \%$ had co-occuring major mental ilness and substance-use disorder. (28). In systematic review and meta-analysis of 29 eligible surveys with 5,684 homeless individuals from seven countries, authors reported that prevalence estimates of psychotic illness range from $2.8 \%$ to $42.3 \%$; major depression from $0.0 \%$ to $40.9 \%$; personality disorder from $2.2 \%$ to $71 \%$; alcohol dependence from $8.5 \%$ to $58.1 \%$ and drug dependence from $4.7 \%$ to $54.2 \%$. The most common mental disorders appeared to be alcohol and drug dependence with random effects pooled prevalence estimates of $37.9 \%$ and $24.4 \%$ respectively (29). From a sample of 266 hostel dwellers in Glasgow, $82 \%$ had cognitive impairment and $78 \%$ were drinking hazardously. The prevalence of alcohol-related brain damage (spectrum of amnesic disorders including Wernicke's Encefalopathy and Korsakoff's Psychosis) was 21\% (30).

\section{Smoking}

Tobacco use is common in homeless populations: approximately three quarters of homeless adults are cigarette smokers a prevalence 4 times that in the U.S. adult population and 2.5 times that among impoverished Americans in general $(32,1)$. Results from the Prague homeless population are very similar. The authors found the prevalence of smoking to be significantly higher among homeless men (93\%) and women $(83 \%)$ compared to the general Czech population, men $38 \%$ and women 35\% (33). A Slovak study implemented in an asylum home showed that $89.4 \%$ of 226 homeless people were smokers while $60.6 \%$ of them consumed too much alcohol (34).

\section{Homeless Children and Youth}

Homelessness negatively impacts child health and development in many ways (35). Children have shown higher rates of acute and chronic health problems (36). Homeless children were 2.5 times as likely to have health problems and 3 times as likely to have severe health problems as housed children (37). Children without a stable home have increased rates of multiple infections, respiratory, gastrointestinal and dermatologic diseases. The prevalence and severity of asthma are increased; they suffer from higher rate of accidents and injuries. Homeless children are at increased risk of abuse; exposure to violence; suffer from higher rates of malnutrition, stunting and obesity (36). Street youth (teenagers and young people below the age of 20-25 years) are exposed to a number of factors that affect their health. Risk of hepatitis B, hepatitis C and HIV infections are higher among street youth than among non-streeet youth. The prevalence of mental health problem, pregnancy and high levels of violence is greater among homeless youth (38). 


\section{Access to Health Care}

There are a number of Internal and External barriers to provide health care for homeless persons. Internal barriers include the denial of health problems by many homeless persons and the pressure to fulfill competing non-financial needs such as for food, clothing and shelter. External barriers include unavailable, fragmented and costly health care services; prejudices and frustrations on the part of Health Profesionals who care for homeless persons (9). Despite a system of Universal Health Insurance, health care access can remain a problem for homeless people. There are financial and non-financial barriers to obtain health care. Non-financial barriers may include general mistrust of health care providers and lack of access to a primary care provider (39). Homeless individuals have high rates of acute health-care use, including Emergency Department visits and Inpatient Admission to hospital (1). 44.91\% of homeless Veterans Affairs (VA) service users were emergency department users, which is nearly three times the rate of domiciled VA Services users (40). In Slovakia, we have similar experience. Hospitalizations of the homeless are more frequent and they last a longer time. The homeless are not registered with their Doctor and try to get health assistance by using emergency services. They have problems with any health system or social insurance (3). The most frequent problems of the health care for homeless are:

- unclear relations between the homeless person, health insurance company and health care providers,

- missing continuity of the health care,

- consequent treatment following hospitalisation,

- chronically ill homeless persons with demanding treatment,

- higher homeless morbidity of some diseases (3).

\section{Older Homeless and Geriatric Syndromes}

In the USA, the authors call the phenomena "aging of the homeless population". The median age of the homeless in San Francisco increased by an average nine years over the 14-year period 1990-2003: this aging rate far exceeds that of the general population. The median total time homeless increased from 12 to 39.5 months. This trend may reflect provider changes or shifts in service utilization (41). The trend in aging of the homeless population will lead to higher need and consumption of health care for the homeless. The American survey compares two groups: younger homeless persons (18 to 49 years old) and older homeless persons (50 years and older). Older homeless persons were 3.6 times more likely to report a chronic medical condition; 2.8 times more likely to not have health insurance. Among medical conditions reported, older homeless respondents were significantly more likely to report having hypertension and arthritis or other musculoskeletal disorders, but comparable rates of chronic respiratory conditions, including asthma and chronic obstructive pulmonary disease (42). At the same time, geriatric syndromes among younger homeless appear more frequently. In a recent study, the authors compared a group of 247 homeless adults (mean age 56.0 years with 765 community adults (mean age 78.1 years) in three population-based cohorts. $30.1 \%$ of homeless people reported difficulty performing at least one activity of daily living; $53.2 \%$ fell in the prior year. Cognitive impairment defined as Mini Mental State Examination score $<24$ was present in $24.3 \%$ of participants, impaired executive function was present in $28.3 \%$ of participants. Self-reported hearing and visual impairment was present among $29.7 \%$ and $30.0 \%$, respectively. Urinary incontinence was reported by $49.8 \%$ of subjects. The study shows that 
older homeless adults have higher rates of most geriatric syndromes compared to the general population (43).

\section{Mortality}

The health status of homeless persons is substantially worse than in other populations. Homeless people have a greatly increased risk of death (12). Among men using shelters for the homeless in Toronto, mortality rates are 8.3 times higher than the mean for 18-24 year olds; 3.7 times higher than the mean for 25-44 years olds; 2.3 times higher than the mean for 45-64 years old (44). In another study the average age at death was 47 years (median, 44 years (range 18 to 86 years). The acquired immunodeficiency syndrome (AIDS) was the leading cause of death among persons 25 to 44 years of age; homicide a leading cause in persons 18 to 24 years of age; heart disease a major cause of death in homeless persons 45 64 years of age. For men 25 to 44 years of age the rate of death from heart disesase was more than threefold higher than in the general population (45). Increased cardiovascular mortality rates in the homeless are attributable to a complex interplay between risk factors. These risks include psycho-social stressors of the daily battle for the necessities of life including food, shelter; safety which along with a decrease in diagnostic, preventative and remedial care results in an increased prevalence and poorer control of risk factors and the co-morbidities (15). Mortality of street youth is about 11 times the expected rate based on age and sex and is mainly caused by suicide and drug overdose (38).

\section{Conclusions}

Problems of providing health care to the homeless depend in every country on the existing health policy and economy (13). Given the raising number of homeless people, our Physicians will more often also have to deal with problems pertaining to diagnostics, treatment and prevention of diseases among the homeless. All of us should be aware that insufficient care for the homeless people means not only aggravation of their health state but it could have negative impacts on health for a much broader group of people passing by with no concern (13).

\section{References}

1. Fazel S, Geddes JR, Kushel M. The health of homeless people in high-income countries: descriptive epidemiology, health consequences, and clinical and policy recommendations. Lancet 2014; 384 (9953): 1529-40.

2. Vereš $\mathbf{M}$. The most frequently causes of homelessness among the seniors. Kontakt 2008; 10 (2): 326-333.

3. Gogoláková P, Dostálová K, Somogyiová E, Vladárová M, Moricová Š. The homeless a problem from the public health view. Verejné zdravotníctvo 2010. http://www.verejnezdravotnictvo.sk

4. Feantsa. ETHOS - European Typology on Homelessness and housing exclusion. 2005. http://www.feantsa.org/spip.php?article120\&lang=en>

5. European Comission, Comission staff working document. Confronting homelessness in The European Union. Brussels: European Comission, 2013: 48 p. http://www.ec.europa.eu

6. Barták M. Homelessness in Czech Republic: the health status of homeless people and it's determinants. Ústí nad Labem: Univerzita J.E.Purkyně, 2011: $200 \mathrm{~s}$.

7. Karvaš B. The situation of the homeless persons in Slovak Republic. Sociálna politika a zamestnanost' 2006; 2: 13-14.

8. Schwarzová G: The social work with the homeless. In: Matoušek O, Koláčková J, Kodymová P (eds.): Social work in practice. Praha: Portál, 2005: 315-330.

9. Plumb JD. Homelessness: care, prevention and public policy. Ann Intern Med 1997; 126 (12): 973-5. 
10. Bošňáková M: Risk factors of homelessness and most frequent infectious and noninfectious diseases among the homeless. Acta chemotherapeutica 2004; 13 (5): 72-80.

11. Laporte A, Rouvel-Tallec A, Grosdidier E et al. Epilepsy among the homeless: prevalence and characteristics. European Journal of Public Health 2005; 16 (5): 584-586.

12. Hwang SW. Homelessness and health. CMAJ 2001; 164 (2): 229-33.

13. Šupková D, Pešek J, Trnka L, Vidovičová H, Volná J. The health care for the homeless. Praha: Grada Publishing, 2007: 64 s.

14. Luder E, Boey E, Buchalter B, Martinez-Weber C. Assessment of the nutritional status of urban homeless adults. Public Health Reports 1989; 104 (5): 451-457.

15. Jones ChA, Perera A, Chow M, Ho I, Ngyuen J, Davachi S. Cardiovascular disease risk among the poor and homeless - what we know so far. Current Cardiology Reviews 2009; 5: 69-77.

16. Brickner PW, Scanlan BC, Cinanan B et al. Homeless persons and health care. Ann Intern Med 1986; 104: 405-409.

17. Tsai J, Rosenbeck RA, Decker SE, Desai RA, Harpaz-Rotem I. Trauma experience among homeless female veterans: correlates and impact on housing, clinical, and psychosocial outcomes. Journal of Traumatic Stress 2012; 25 (6): 624-32.

18. Topolovec-Vranic J, Ennis N, Colantonio A. et al. Traumatic brain injury among people who are homeless: a systematic review. BMC 2012; 12: 1059.

19. Hwang SW, Colantonio A, Chiu S et al. The effect of traumatic brain injury on the health of homeless people. CMAJ 2008; 179(8): 179-84.

20. Raoult D, Foucault C, Brouqui P. Infections in the homeless. The Lancet Infectious Diseases 2001; 1(2): 77-84.

21. Plevneshi A, Svoboda T, Armstrong I et al. Population-based surveillance of invasive pneumococcal disease in homeless adults in Toronto. PloS One 2009; 4(9): e 7255. doi:10.1371/journal.pone.0007255.

22. Beijer U, Wolf A, Fazel S. Prevalence of tuberculosis, hepatitis $\mathrm{C}$ virus, and HIV in homeless people: a systematic review amd meta-analysis. Lancet Infect Dis 2012; 12: 859-70.

23. Kubín M, Kalina P, Jágrová Z, Švandová E. Foreigners and homeless - new epidemiological and social factors in the control of tuberculosis in Prague. Prakt Lék 2010; 90(6): 352-7.

24. Trnka L. The prevalence of tuberculosis in 21 th century and problem of homeless in Czech Republic. In: Health care for homeless people in Czech republic. [Šupková, D. a kol. - eds]. Praha: Grada Publishing, 2007: 44-50.

25. Culhane DP, Gollub E, Kuhn R, Shpaner $\mathrm{M}$. The co-occurence of AIDS and homelessness: databases for AIDS surveillance and public shelter utilisation in Philadelphia. J Epidemiol Community Health 2001; 55(7): 515-20.

26. Roy E, Haley N, Lemire N, Boivin JF, Leclerc P, Vincelette J. Hepatitis B virus infection among street youth in Montreal. CMAJ 1999; 161(6): 689-93.

27. Volf V, Marx D, Pliskova L, Sumegh L, Celko A. A survey of hepatitis B and C prevalence amongst the homeless community of Prague. European Journal of Public Health 2007; 18 (1): 44-7.

28. Wolfson IS. Homelessness and health. Medicine and Health Rhode Island 2006; 89 (10): 336-8.

29. Fazel S, Khosia V, Doll H, Geddes J. The prevalence of mental disorders among the homeless in Western countries: systematic review and meta-regression analysis. PLoS Medicine 2008; 5(12): e 225. doi:10.1371/ journal.p.med.0050225.

30. Gilchrist G, Morrison DS. Prevalence of alcohol related brain damage among homeless hostel dwellers in Glasgow. European Journal of Public Health 2005; 15(6): 587-8. 
31. Perry J, Craig TKJ. Homelessness and mental health. Trends in Urology and Men's Health 2015; 6 (2): 19-21.

32. Baggett TP, Tobey ML, Rigotti NA. Tobacco use among homeless people - addressing the neglected addiction. N Engl J Med 2013; 369(3): 201-4.

33. Kubisová D, Adámková V, Lánska V, Dlouhý P, Rambousková J, Anděl M. Higher prevalence of smoking and lower BMI, waist circumference, cholesterol and triacylglyceride levels in Prague's homeless compared to a a majority of the Czech population. BMC Public Health 2007; 7: 51.

34. Kasanová A, Turček K. A look on unwanted habits and other mental morbidities of residents of asylum houses. Alkoholizmus a drogové závislosti (Protialkoholický Obzor) 2004; 39 (4-5): 211-6.

35. Weinreb L, Goldberg R, Bassuk E, Perloff J. Determinants of health and service use patterns in homeless and low-income housed children. Pediatrics 1998; 102 (3): 554562.

36. Council on Community Pediatrics. Providing care for children and adolescent facing homelessness and housing insecurity. Pediatrics 2013; 131(6): 1206-10.

37. Berti LC, Zylbert S, Rolnitzky L. Comparison of health status of children using a school-based health center for comprehensive care. J Pediatr Health Care 2001; 15 (5): 244-250.

38. Boivin JF, Roy E, Haley N, Galbauld du Fort G. The health of street youth. CJPH 2005; 96 (6), 432-7.
39. Hwang SW, Ueng JJM, Chiu S. et al. Universal health insurance and health care access for homeless persons. Am J Public Health 2010; 100(8): 1454-61.

40. Tsai J, Rosenbeck RA. Risk factors for ED use among homeless veterans. Am J Emerg Med 2013; 31(5): 855-59.

41. Hahn JA, Kushel MB, Bangsberg DR, Riley E, Moss AR. Brief report: the aging of the homeless population: fourteen-year trend in San Francisco. J Gen Intern Med 2006; 21 : 775-778.

42. Garibaldi B, Conde-Martel A, O'Toole TP. Self-reported comorbidities, perceived needs, and sources for usual care for older and younger homeless adults. J Gen Intern Med 2005; 20(8): 726-730.

43. Brown RT, Kiely DK, Bharel M, Mitchell SL. Geriatric syndromes in older homeless adults. J Gen Intern Med 2011; 27 (1): 1622.

44. Hwang SW. Mortality among men using homeless shelters in Toronto, Ontario. JAMA 2000; 283: 2152-7.

45. Hwang SW, Orav EJ, O'Connell JJ, Lebow JM, Brennan TA. Causes of death in homeless adults in Boston. Ann Intern Med 1997; 126 (8): 625-628.

\section{Corresponding author}

\section{Bartošovič}

St. Elisabeth University of Health

and Social Sciences, Bratislava

Doležalova 12, 90901 Skalica, Slovak republic

Tel: +421 346645332

Email: ivan.bartosovic@gmail.com 